\title{
Lentiviral-mediated gene therapy restores B cell tolerance in Wiskott-Aldrich syndrome patients
}

\author{
Francesca Pala, ${ }^{1,2}$ Henner Morbach, ${ }^{2}$ Maria Carmina Castiello, ${ }^{1}$ Jean-Nicolas Schickel, ${ }^{2}$ Samantha Scaramuzza, ${ }^{1}$ \\ Nicolas Chamberlain, ${ }^{2}$ Barbara Cassani, ${ }^{3,4}$ Salome Glauzy, ${ }^{2}$ Neil Romberg, ${ }^{5}$ Fabio Candotti, ${ }^{6}$ Alessandro Aiuti, ${ }^{1,7}$ \\ Marita Bosticardo, ${ }^{1}$ Anna Villa, ${ }^{1,4}$ and Eric Meffre ${ }^{2}$ \\ 'San Raffaele Telethon Institute for Cene Therapy (TIGET), IRCCS San Raffaele Scientific Institute, Milan, Italy. ²Department of Immunobiology, Yale University School of Medicine, New Haven, Connecticut, USA. \\ ${ }^{3}$ Humanitas Clinical and Research Center, Rozzano, Italy. ${ }^{4}$ IRGB CNR, Milan Unit, Milan, Italy. ${ }^{5}$ Department of Pediatrics, Division of Allergy and Clinical Immunology, Yale University School of Medicine, New Haven, \\ Connecticut, USA. ${ }^{6}$ Cenetics and Molecular Biology Branch, National Human Cenome Research Institute, NIH, Bethesda, Maryland, USA. Department of Systems Medicine, Tor Vergata University, Rome, Italy.
}

\begin{abstract}
Wiskott-Aldrich syndrome (WAS) is an X-linked immunodeficiency characterized by microthrombocytopenia, eczema, and high susceptibility to developing tumors and autoimmunity. Recent evidence suggests that $B$ cells may be key players in the pathogenesis of autoimmunity in WAS. Here, we assessed whether WAS protein deficiency (WASp deficiency) affects the establishment of $B$ cell tolerance by testing the reactivity of recombinant antibodies isolated from single B cells from 4 WAS patients before and after gene therapy (GT). We found that pre-GT WASp-deficient B cells were hyperreactive to B cell receptor stimulation (BCR stimulation). This hyperreactivity correlated with decreased frequency of autoreactive new emigrant/transitional B cells exiting the BM, indicating that the BCR signaling threshold plays a major role in the regulation of central B cell tolerance. In contrast, mature naive B cells from WAS patients were enriched in self-reactive clones, revealing that peripheral B cell tolerance checkpoint dysfunction is associated with impaired suppressive function of WAS regulatory T cells. The introduction of functional WASp by GT corrected the alterations of both central and peripheral B cell tolerance checkpoints. We conclude that WASp plays an important role in the establishment and maintenance of $B$ cell tolerance in humans and that restoration of WASp by GT is able to restore B cell tolerance in WAS patients.
\end{abstract}

\section{Introduction}

Wiskott-Aldrich syndrome (WAS) is a rare X-linked disease in which immunodeficiency associates with thrombocytopenia and a high risk to develop tumors and autoimmune manifestations (1). Mutations in the WAS gene encoding a key regulator protein of the cytoskeleton lead to a defective expression of the molecule in hematopoietic cells (2). Besides immunodeficiency, autoimmunity represents a frequent clinical condition that, when present, increases the severity of the disease and defines a high-risk group with poor prognosis $(3,4)$. Combined studies in mice and patients have been performed to elucidate the contribution of WAS protein (WASp) in tolerance induction, particularly focusing on WASp-deficient T cells. Defects in peripheral tolerance caused by alterations in regulatory and effector $\mathrm{T}$ cell compartments have been demonstrated to play a major role in self-tolerance breakdown both in mouse models and patients (5-8). The analysis of $\mathrm{Was}^{-/-}$mice clearly points out defects in B cells, suggesting impairment in the removal of autoreactive B cells (9-11). B cells from WAS patients show defects in migration and adhesion because of defective actin polymerization and poor migration toward S1P,

\section{Related Commentary: p. 3748}

Authorship note: Anna Villa and Eric Meffre contributed equally to this work. Conflict of interest: The authors have declared that no conflict of interest exists. Submitted: April 8, 2015; Accepted: July 16, 2015.

Reference information: J Clin Invest. 2015;125(10):3941-3951. doi:10.1172/JCI82249. as well as SDF1 $\alpha(12-14)$. B cell counts usually decrease with age in addition to a skewed distribution of serum immunoglobulins and impaired response to $\mathrm{T}$ cell-independent antigens $(15,16)$. In addition, WASp plays an important role in the maintenance of $\mathrm{B}$ cell homeostasis in humans, as illustrated by the unusual expansion of $\mathrm{CD} 21^{-/ 10} \mathrm{~B}$ cells enriched in autoreactive clones in WAS patients irrespectively of age and disease severity scores $(14,17$, 18). Human WASp-deficient memory B cells showed a preferential usage of variable Ig heavy chain VH4-34, a gene segment encoding intrinsically self-reactive $\mathrm{B}$ cell receptors (BCRs) recognizing the I/i antigens $(19,20)$ and displayed reduced in vivo proliferation and decreased somatic hypermutation $(14,17)$. Perturbations in B cell homeostasis in WAS patients led us to further assess whether the absence of WASp may impair B cell tolerance checkpoints responsible for the removal of developing autoreactive $B$ cells (21). A central B cell tolerance checkpoint, which depletes many polyreactive and antinuclear clones in the BM, appears to be mostly controlled by B cell intrinsic factors, since decreased BCR signaling and Toll-like receptor (TLR) 7 and 9 function lead to an impaired counterselection of autoreactive B cells (22-25). On the other hand, peripheral $\mathrm{B}$ cell tolerance is mostly regulated by $\mathrm{B}$ cell extrinsic factors, such as regulatory T cells (Treg) (24, 26-29). We thus investigated if the absence of WASp could affect central and peripheral $\mathrm{B}$ cell checkpoints, by evaluating the frequency of $\mathrm{B}$ cells expressing autoreactive antibodies at a single-cell level. We therefore analyzed the frequency of clones expressing polyreactive, HEp-2, or antinuclear antibodies (ANAs) in new emigrant/ 
A
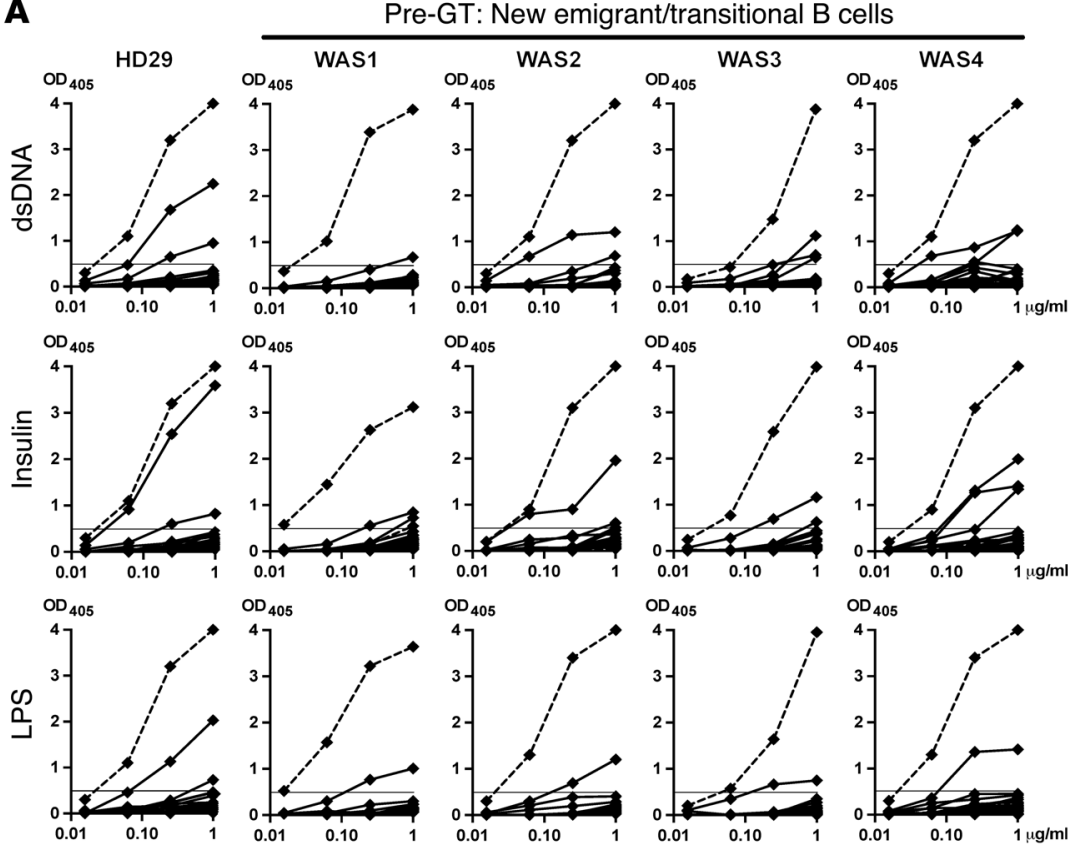

$\mathrm{OD}_{405}$

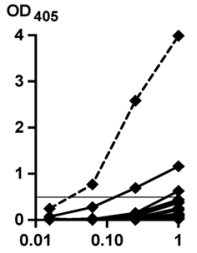

\section{$\mathrm{OD}_{405}$}
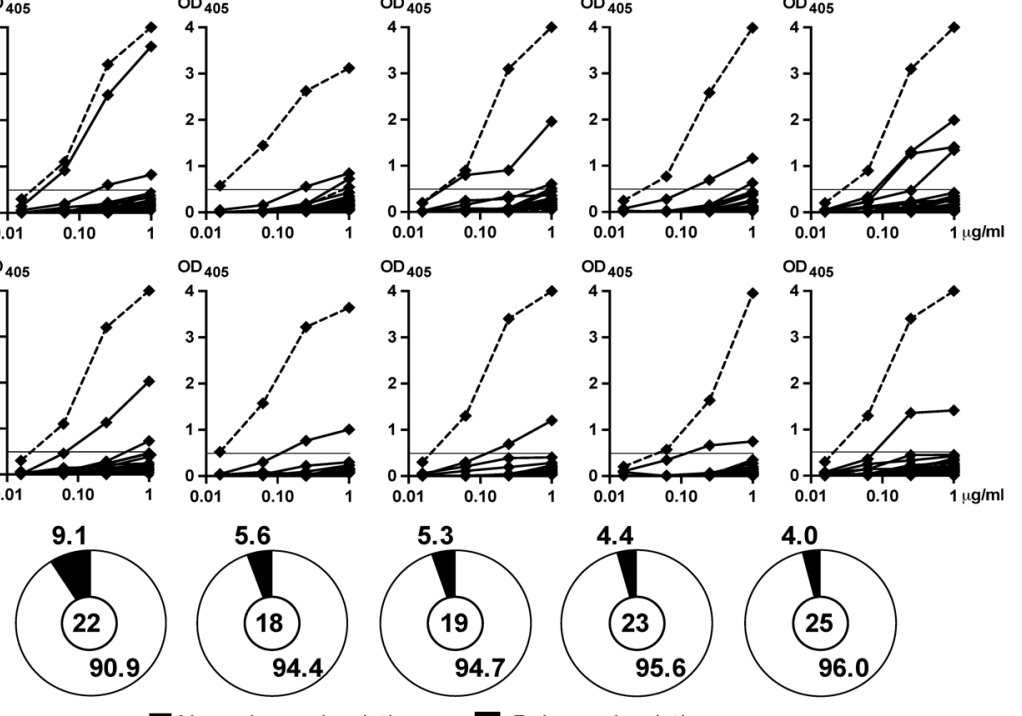

$\square$ Nonpolyreactive (\%)

Polyreactive (\%)
B

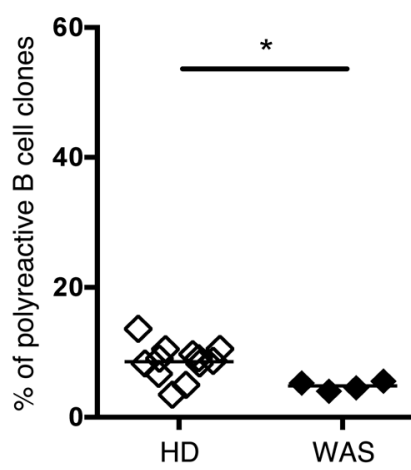

D

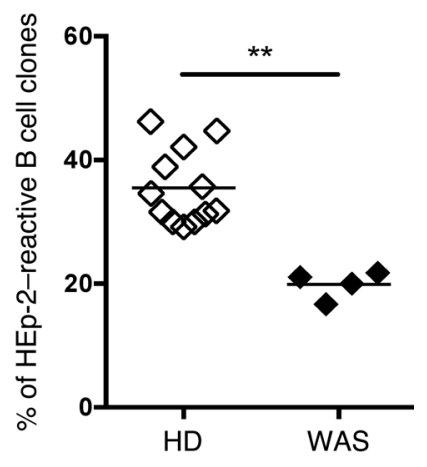

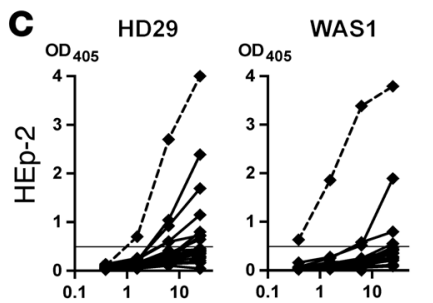
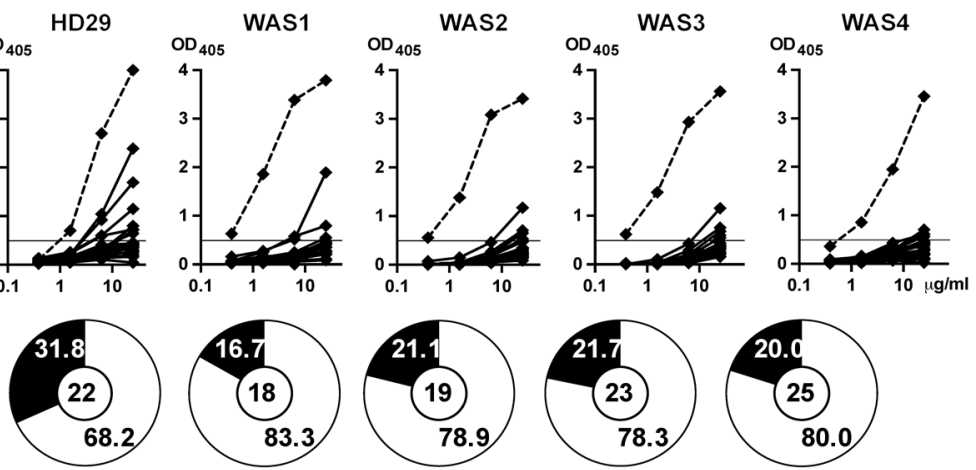

HEp-2-reactive (\%)

E

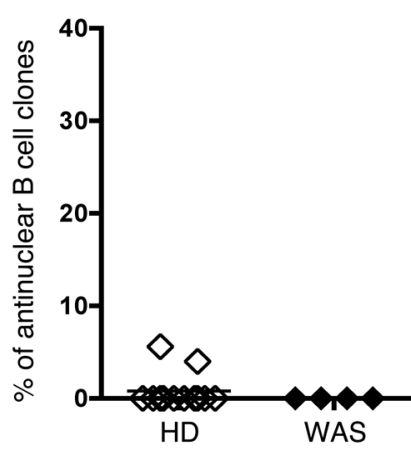

Figure 1. WAS patients display a more stringent central B cell tolerance. (A and C) Recombinant antibodies expressed by new emigrant/transitional $\left(C D 19+C D 10^{+} \mid g^{M^{h i} C D 21^{\circ} C D 27}\right)$ B cells from a representative HD (HD29) and 4 WAS patients were tested by ELISA for reactivity against dsDNA, insulin, LPS (A), and HEp-2 lysate (C). Antibodies were considered polyreactive when they recognized all 3 antigens in A. Dotted lines show ED38+ control and horizontal lines define cutoff $\mathrm{OD}_{405}$ for positive reactivity. The frequencies of reactive and nonreactive clones are summarized in pie charts, with the total number of clones tested shown in the center. (B, D, and E) The frequencies of polyreactive (B), HEp-2-reactive (D), and antinuclear (E) new emigrant/transitional B cells are shown for HDs (open diamonds) and WAS patients (filled diamonds). Each symbol represents an individual, and horizontal bars display means. Differences were analyzed for statistical significance using Mann-Whitney test. ${ }^{*} P<0.05$ and ${ }^{* *} P<0.01$.

transitional and mature naive B cells isolated from WAS patients, and we tested if the autologous transplant of WAS gene-corrected hematopoietic stem cells (HSCs), recently demonstrated by our group to be a feasible alternative therapeutic approach, could restore $\mathrm{B}$ cell tolerance in WAS patients $(30,31)$. We found that WASp deficiency altered both central and peripheral B cell tolerance checkpoints and that lentiviral-mediated gene correction is highly efficient at restoring B cell tolerance in WAS patients.

\section{Results}

Altered central B cell tolerance checkpoint in WAS patients. Most developing B cell clones expressing polyreactive antibodies and ANAs are removed in the $\mathrm{BM}$ at a central $\mathrm{B}$ cell tolerance checkpoint during early B cell development (25). To evaluate whether this initial selection is functional in the absence of WASp, we cloned antibodies that were expressed by single $\mathrm{CD} 19^{+} \mathrm{CD} 10^{+} \operatorname{IgM}^{\mathrm{hi}} \mathrm{CD} 21^{\mathrm{lo}} \mathrm{CD} 27^{-}$new emigrant/transitional B cells sorted from 4 WAS pediatric patients 
A

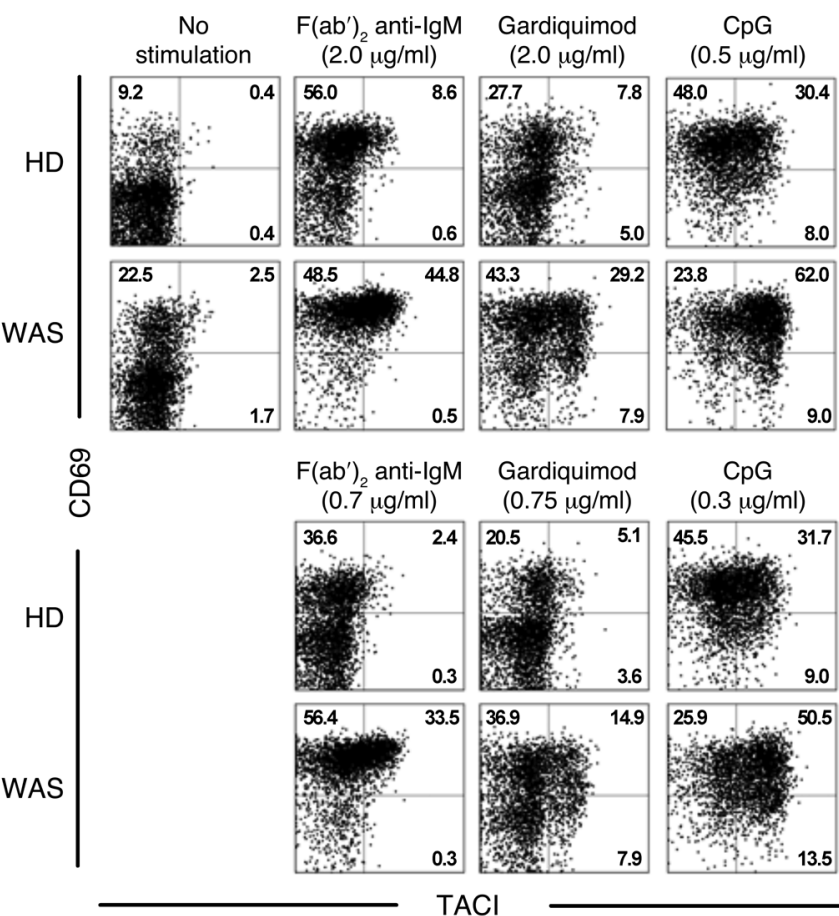

B

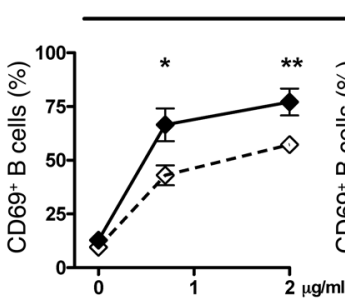

Gardiquimod

$\mathrm{CpG}$
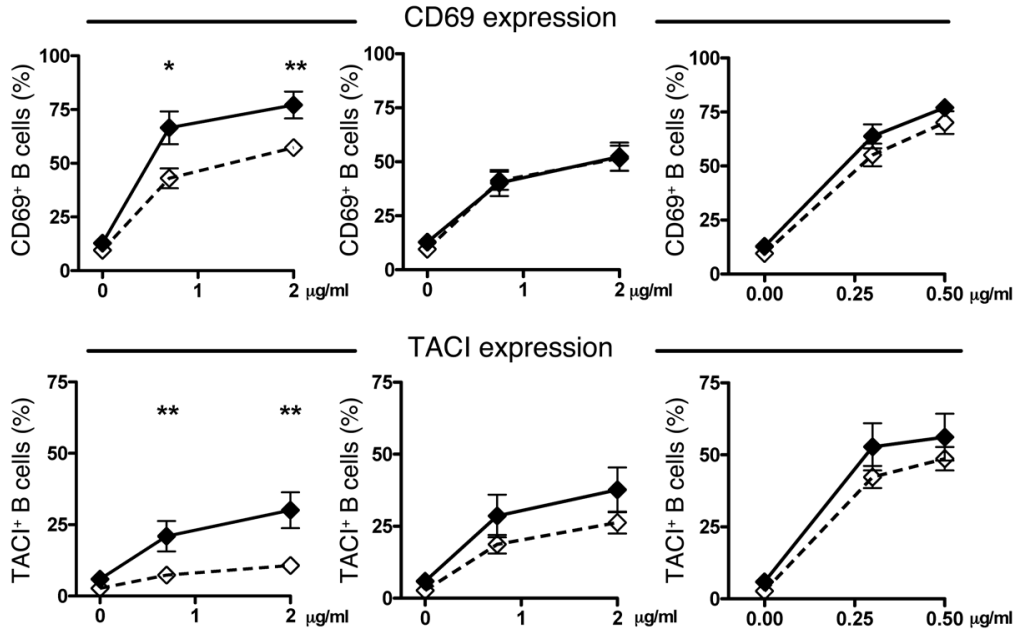

TACI expression
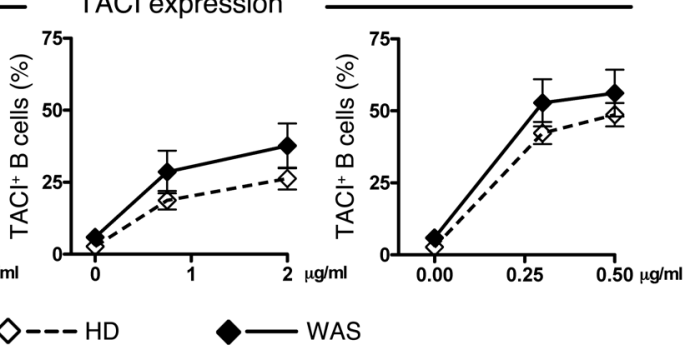

Figure 2. Increased BCR-, TLR7-, and TLR9-induced B cell activation in WAS patients. (A) Surface expression of CD69 and $\mathrm{TACl}$ on $\mathrm{CD} 19^{+} \mathrm{CD} 21^{+} \mathrm{CD} 27^{-}$naive $\mathrm{B}$ cells of a representative HD and a WAS patient after no stimulation or in vitro stimulation with $F\left(a b^{\prime}\right)$, anti-IgM, the TLR7 ligand gardiquimod, or the TLR9 ligand CPC ODN2006 for 2 days at 2 different concentrations (indicated above dot plots). (B) Mean Frequency \pm SEM of $\mathrm{CD}^{\circ} 9^{+}$and $\mathrm{TACl}^{+} \mathrm{B}$ cells from $\mathrm{HDs}$ (open diamond;

$n=14$ ) and WAS patients (filled diamond; $n=8$ ) after 2 days of in vitro activation. Data are representative of 7 independent experiments. Differences were analyzed for statistical significance using Student's $t$ test. $\left({ }^{*} P<0.05\right.$ and ${ }^{* *} P<0.01$ ).

as compared with healthy donors (HDs) (4\%-5.6\% of clones, compared with 5\%-11.5\%) (Figure 1, A and B). In addition, the proportion of new emigrant/transitional B cells that expressed antibodies recognizing antigens in HEp-2 cell line extracts was also significantly decreased in WAS patients compared with controls $(16.7 \%-21.7 \%$ in WAS patients vs. $29.2 \%-44.7 \%$ in HDs; Figure 1, C and D). Moreover, new emigrant/ transitional $\mathrm{B}$ cells of WAS patients were devoid of nuclear reactive clones (Figure 1E). Hence, WASp deficiency induces an enhanced removal of developing autoreactive B cells in the BM of WAS patients, who therefore display a more stringent central B cell tolerance checkpoint than HDs.

WASp deficiency induces increased BCR responses. $\mathrm{B}$ cell intrinsic pathways initiated by BCRs and, potentially, TLRs regulate central B cell tolerance checkpoints, as illustrated by the impaired removal in the BM of developing autoreactive B cells in patients with gene defects crippling BCR and TLR signaling (25). Since WASp deficiency resulted in a more efficient depletion of autoreactive clones in the BM, we tested if B cell responses to BCR and TLR stimulation were affected by the absence of functional WASp. Purified B cells freshly isolated from WAS patients and HDs were stimulated in vitro with different concentrations of $\mathrm{F}\left(\mathrm{ab}^{\prime}\right)_{2}$ anti-human IgM that triggers BCRs, gardiquimod (TLR7 agonist), or CpG (TLR9 agonist) for 2 days. We found that the induction after BCR stimulation of TACI and CD69 was significantly enhanced on $\mathrm{CD} 19^{+} \mathrm{CD} 21^{+} \mathrm{CD} 27^{-}$ naive $\mathrm{B}$ cells from WAS patients as compared with their HD counterparts (Figure 2, A and B). Increased BCR

(Supplemental Figure 1; supplemental material available online with this article; doi:10.1172/JCI82249DS1), whose clinical features are described in Supplemental Table 1. Heavy chain gene repertoire analysis revealed that new emigrant/transitional B cells from WAS patients displayed significantly longer IgH complementarity-determining region 3 (CDR3) loops, suggesting an altered central B cell tolerance checkpoint in the absence of functional WASp (Supplemental Figure 2A and Supplemental Table 1). The reactivity of recombinant antibodies against dsDNA, insulin, and lipolysaccharide (LPS) was tested by ELISA assay to determine their polyreactivity, as previously described (Supplemental Tables 2-5) (21). We found that the proportion of polyreactive new emigrant/ transitional B cells was significantly decreased in all WAS patients responses in WASp-deficient $\mathrm{B}$ cells were also evidenced by the significantly increased expression of CD25 and CD86 after F(ab') anti-human IgM stimulation (Supplemental Figure 3). These enhanced BCR responses likely result from the increased cellsurface IgM expression on $\mathrm{CD}^{1} 9^{+} \mathrm{CD} 10^{-} \operatorname{IgM}^{+} \mathrm{CD} 21^{+} \mathrm{CD} 27^{-}$mature naive B cells from WAS patients (Supplemental Figure 4). In contrast, the expressions of BCR-associated complex molecules CD19 and CD21 were found to be decreased on WASp-deficient mature naive $B$ cells, revealing a differential regulation of cell-surface expression of BCRs and its coreceptor by WASp (Supplemental Figure 4). Naive B cells from WAS patients also displayed a tendency to increase TACI and CD69 expression after TLR7 and TLR9 stimulation, although CD25 and CD86 regulation did not follow that 
A
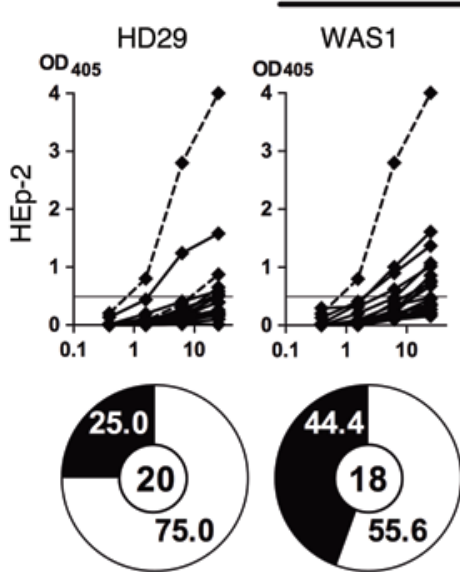

Non-HEp-2-reactive (\%)

D
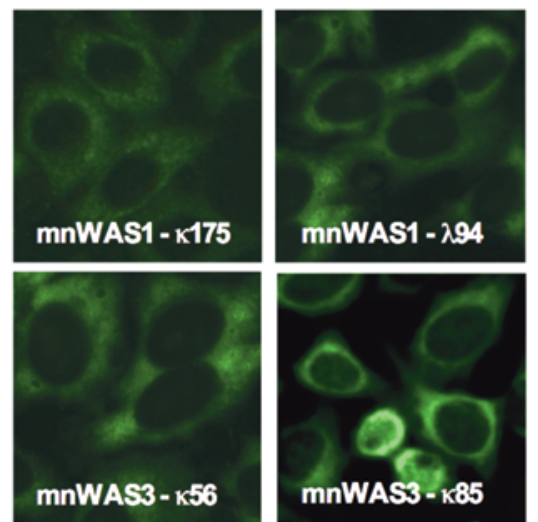

Pre-GT: Mature naive B cells
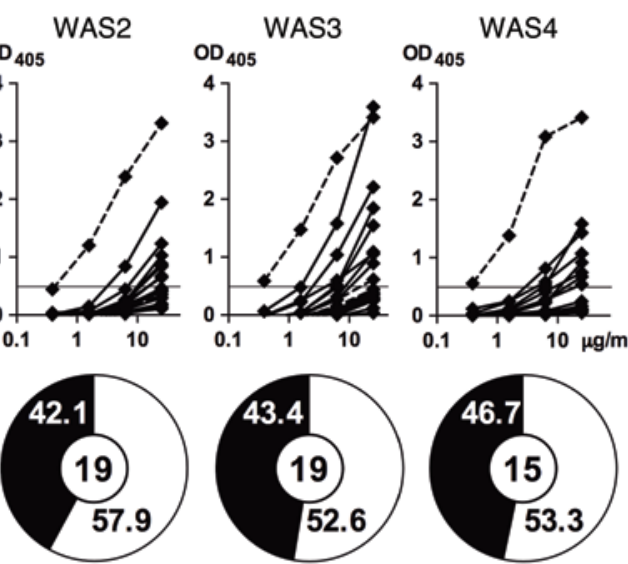

HEp-2-reactive (\%)
B

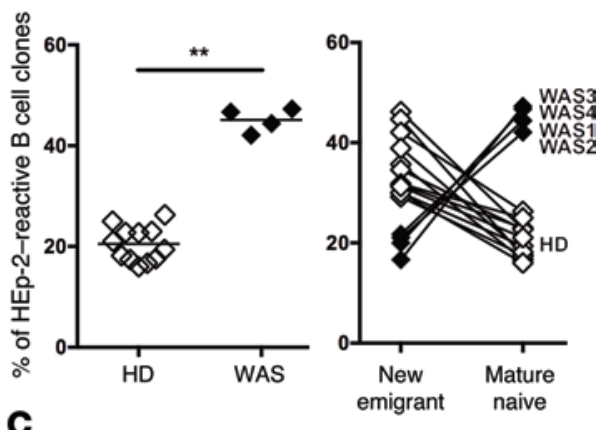

C

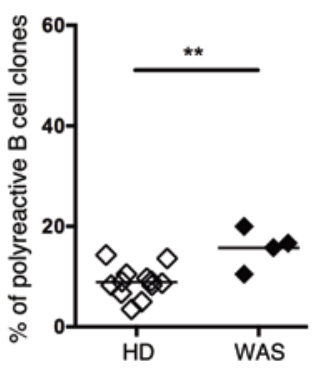

E
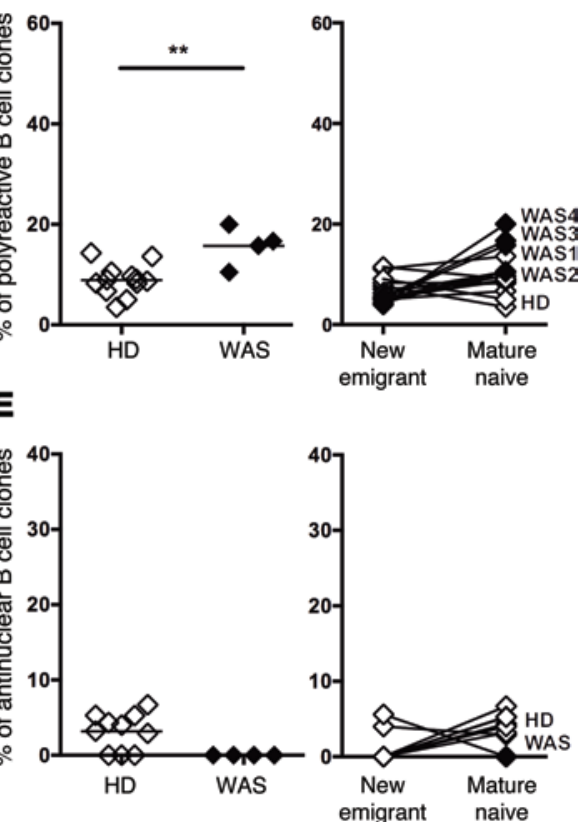

Figure 3. The peripheral B cell tolerance checkpoint is defective in WAS patients. (A) Recombinant antibodies expressed by mature naive (CD19+ $\left.\mathrm{CD}^{-} \mathrm{CD}^{-} 1^{+} \mathrm{IgM} \mathrm{CM}^{+} \mathrm{CD} 7^{-}\right) \mathrm{B}$ cells from a representative $\mathrm{HD}$ (HD29) and 4 WAS patients were tested by ELISA for reactivity against HEp-2 cell lysate. Dotted lines show ED $38^{+}$control. Horizontal lines show cutoff $\mathrm{OD}_{405}$ for positive reactivity. The frequencies of HEp-2 reactive and non-HEp-2-reactive clones are summarized in the pie charts, with the number of antibodies tested shown in the center. (B, C, and E) Frequencies of HEp-2-reactive (B), polyreactive (C), and antinuclear (E) mature naive B cells are summarized for HDs and WAS patients (left panels). The evolution of the frequencies of HEp-2-reactive (B), polyreactive (C), and antinuclear (E) B cell clones between the new emigrant and mature naive B cell stages is represented for HDs (open diamonds) and WAS patients (filled diamonds) (right panels). Each symbol represents an individual, and horizontal bars display means. (D) Autoreactive antibodies expressed by WAS mature naive $B$ cells do not recognize nuclear structures and react against cytoplasmic structures. Original magnification, $\times 40$. (B, C, and E) Differences were analyzed for statistical significance using Mann-Whitney test. ${ }^{*} P<0.05$ and ${ }^{* *} P<0.01$.

trend (Figure 2, A and B, and Supplemental Figure 3). These findings show that B cells lacking WASp are more responsive to BCRs, suggesting that B cell hyperresponsiveness may account for the increased counterselection of autoreactive B cells in the BM.

Defective peripheral B cell tolerance checkpoint in WAS patients. The frequency of autoreactive clones further decreases in HDs between new emigrant/transitional and mature naive B cells, thereby identifying a second peripheral B cell tolerance checkpoint likely reflecting complex processes of negative and positive selection of B cells $(21,25)$. To assess whether the absence of functional WASp could affect this peripheral checkpoint, we tested the reactivity of recombinant antibodies expressed by single mature naive B cells from WAS patients and HDs against HEp2 cell lysates by ELISA (Supplemental Tables 6-9 and ref. 21). An altered peripheral $\mathrm{B}$ cell tolerance checkpoint in the absence of functional WASp was suggested by the abnormal IgH repertoire of mature naive B cells from WAS patients characterized by significantly longer IgH CDR3 loops, as well as an increased usage of VH4-34, a gene segment with intrinsic self-reactivity (Supplemental Figure 2 and refs. 19, 20). The analysis of antibody reactivity revealed that the frequency of HEp-2-reactive clones was significantly increased in all 4 WAS patients $(42.1 \%-46.7 \%)$ as compared with HDs (16\%-26.3\%), revealing a defective peripheral B cell tolerance checkpoint (Figure 3, A and B). While HEp-2 reactivity in HDs decreases during the transition from new emigrant/ transitional to mature naive $\mathrm{B}$ cells and identifies the peripheral $\mathrm{B}$ cell tolerance checkpoint, the absence of functional WASp instead favored the accumulation of HEp-2-reactive B cells in the mature naive B cell compartment of WAS patients (Figure 3B). An impaired peripheral $\mathrm{B}$ cell tolerance checkpoint in WAS deficiency 
A
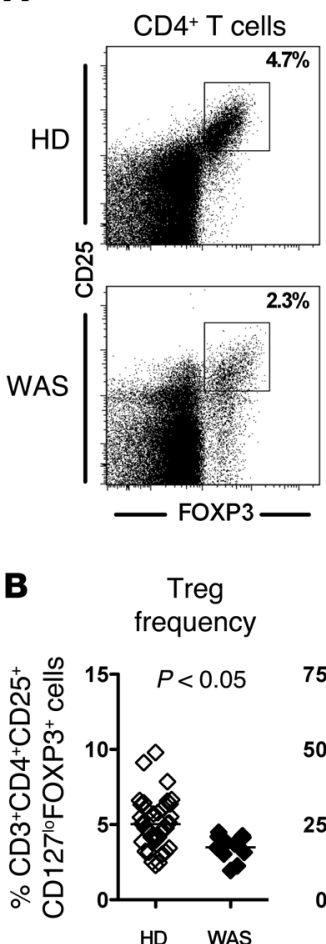
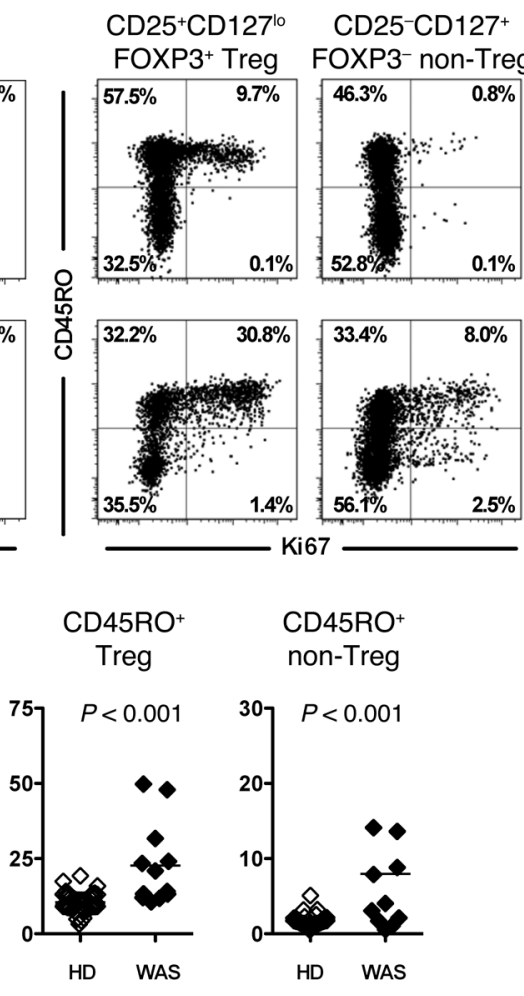

Figure 4. WASp-deficient Tregs display reduced suppressive capacity. (A) Representative flow cytometry dot plots showing the analysis of CD25 and FOXP3 expression with gating on CD4 ${ }^{+}$cells (left panel) or CD45RO and Ki67 with gating on CD4+CD25+CD127/ FOXP3 ${ }^{+}$Treg (middle panel) or CD4+CD25-

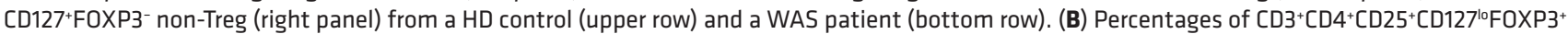
Tregs among total CD4+ cells (left) and $\mathrm{Ki}^{+} 7^{+}$cells among CD45RO+ Tregs (middle) or among CD45RO+ non-Tregs of 45 HDs (open diamonds) and 12 WAS patients (filled diamonds). (C and D) Representative histograms of Treg-mediated suppression of autologous and heterologous CFSE-labeled Tresp from a WAS patient and HD control. Dashed lines display nonstimulated Tresp cells (C). The autologous and heterologous suppressive activities of Tregs from HD controls and WAS patients are summarized in D. (B and D) Differences were analyzed for statistical significance using Mann-Whitney test.

was further evidenced by the increased frequency of polyreactive mature naive B cells, which ranged from $10.5 \%-20.0 \%$ in WAS patients vs. 3.5\%-13.6\% in HDs (Figure 3C and Supplemental Figure 5). The reemergence in the mature naive $\mathrm{B}$ cell compartment of WAS patients of polyreactive clones that were rare in new emigrant/transitional B cells may reflect a positive selection of autoreactive clones in WASp-deficient mature naive B cells (Figure 3C). However, using indirect immunofluorescence assays with HEp-2 cell-coated slides, we failed to identify antinuclear mature naive B cells in WAS patients (Figure 3, D and E). Indeed, staining of HEp-2-coated slides revealed cytoplasmic recognition patterns for autoreactive antibodies expressed by WASp-deficient B cells (Figure 3D). Hence, despite an enhanced counterselection of autoreactive $B$ cells in the BM, WAS patients display an increased frequency of autoreactive mature naive $B$ cells, revealing a defective peripheral $\mathrm{B}$ cell tolerance characterized by the positive selection of WASp-deficient autoreactive clones.

WAS patients display decreased frequency of Tregs with altered suppressive capacities. Tregs play an important role in the regulation of the peripheral B cell tolerance checkpoint $(24,26,29)$. Previous reports demonstrated impaired Treg suppressive function in WAS patients that may account for their impaired peripheral B cell tolerance checkpoint (5-8). We therefore evaluated the $\mathrm{CD} 4^{+} \mathrm{CD} 25^{+} \mathrm{CD} 127^{\mathrm{lo}} \mathrm{FOXP} 3^{+}$Treg compartment of WAS patients, including the WAS patients enrolled in the GT trial and additional WAS patients, and tested their ability in vitro at suppressing $\mathrm{T}$ responder (Tresp) proliferation. WAS patients displayed significantly decreased frequencies of $\mathrm{CD} 4^{+} \mathrm{CD} 25^{+} \mathrm{CD} 127^{10-}$ FOXP3 $^{+}$Tregs compared with HDs (Figure 4 , A and B). In addition, WASp-deficient Tregs contained an increased proportion of $\mathrm{CD} 45 \mathrm{RO}^{+}$clones that expressed the Ki67 proliferation marker in comparison to HDs (Figure 4, A and B). Tregs from WAS patients also appeared activated, as illustrated by their increased CTLA4 expression (Supplemental Figure 6). Enhanced proliferation in the absence of functional WASp was not restricted to Tregs because Ki67 expression was also significantly higher in $\mathrm{CD}^{+}$non-Tregs of WAS patients, indicative of dysregulated $\mathrm{T}$ cell homeostasis (Figure 4, A and B). In agreement with this observation, non-Tregs also displayed increased CD25/IL-2RA but decreased CD127/IL-7RA expression (Supplemental Figure 6). Hence, WASp deficiency is characterized by decreased Treg frequency associated with altered $\mathrm{T}$ cell homeostasis, suggesting Treg function may be impaired. $\mathrm{CD}_{4} 5 \mathrm{RO}^{+}$Tregs that coexpress Ki67 were previously reported to express proinflammatory cytokines and to display reduced suppressive abilities (32-35). We therefore assessed Treg function by testing the capability of $\mathrm{CD} 4{ }^{+} \mathrm{CD} 25^{\text {hi }} \mathrm{CD} 127^{\text {lo }} \mathrm{T}$ cells isolated from HDs and WAS patients to suppress the proliferation induced by beads coated with 
A

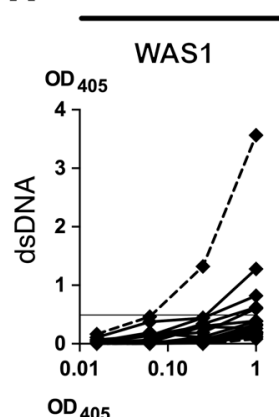

Post-GT: New emigrant/transitional B cells
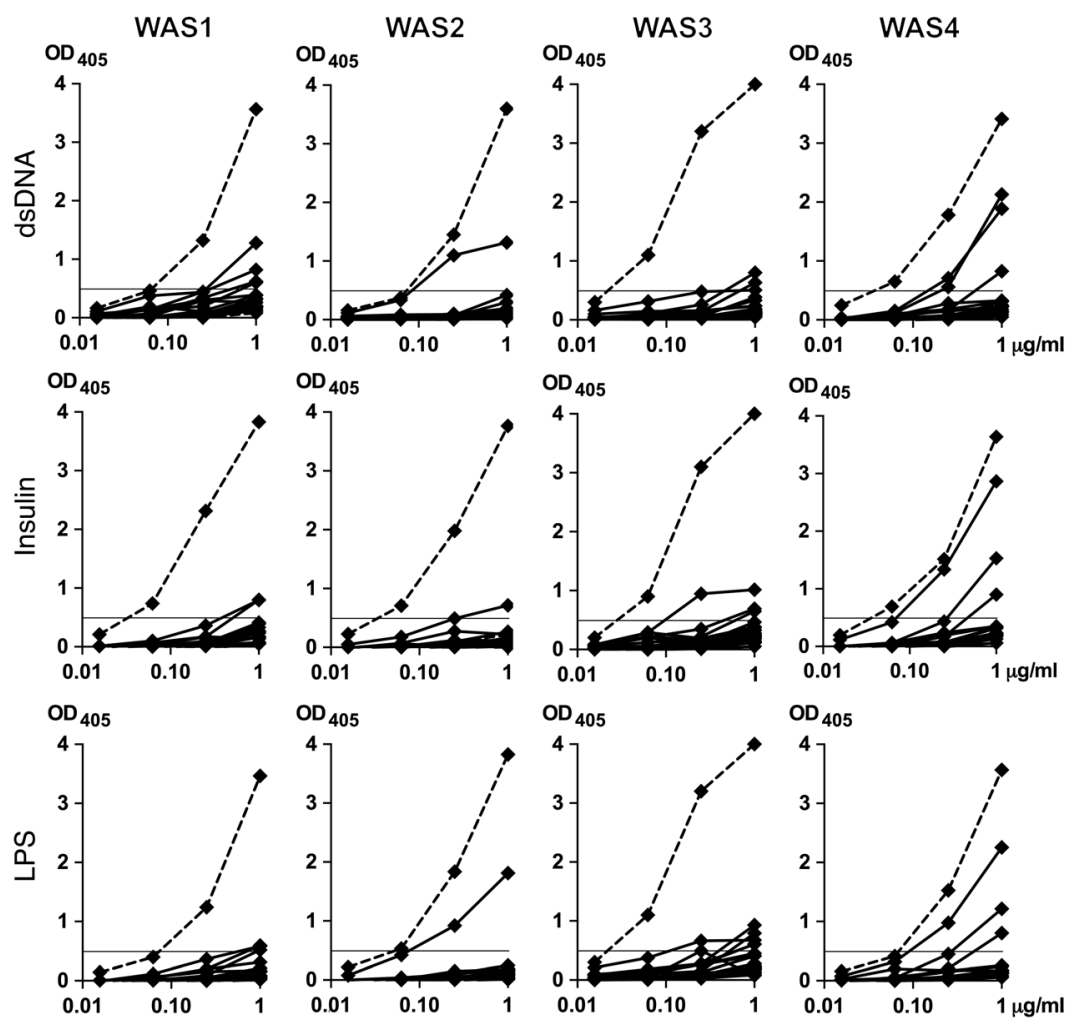

$\mathrm{OD}_{405}$
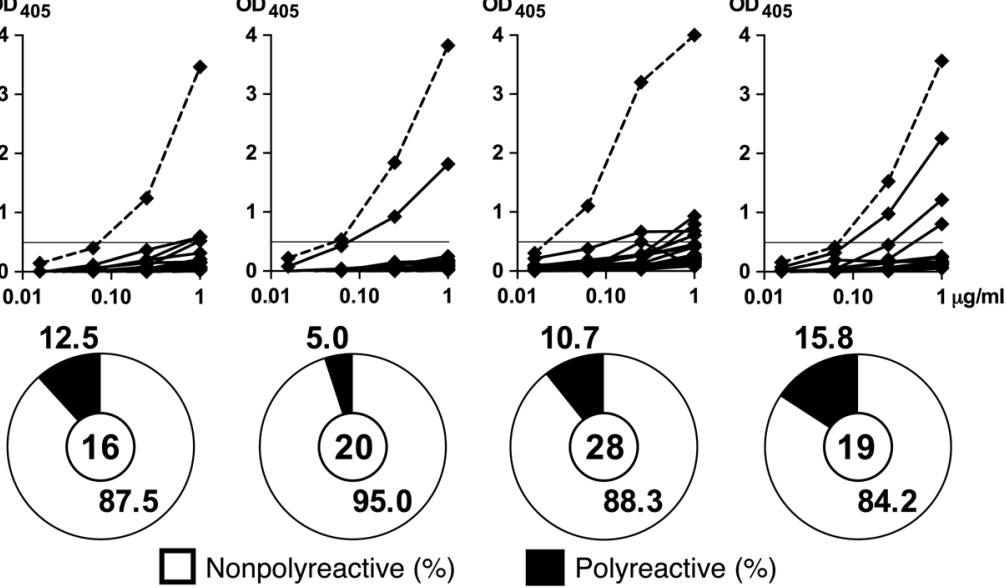

Polyreactive (\%)
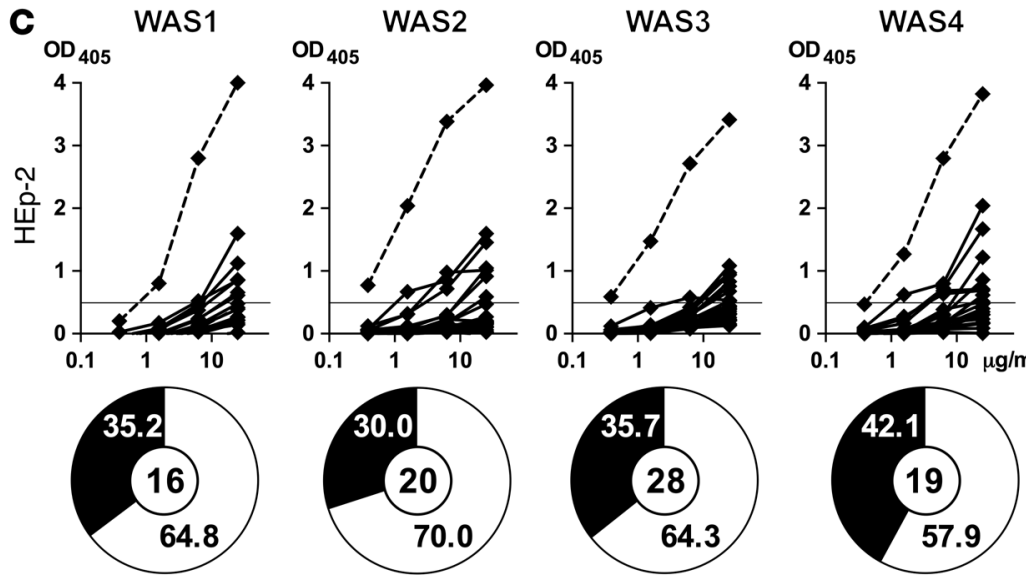

HEp-2-reactive (\%)
B

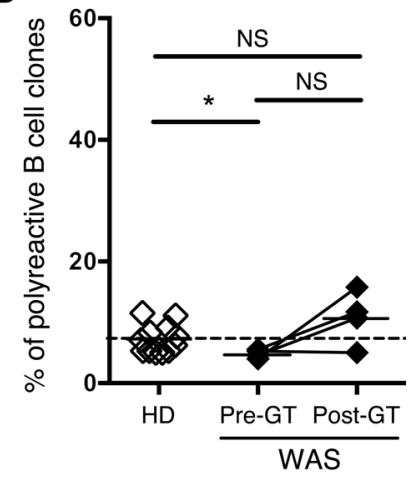

D

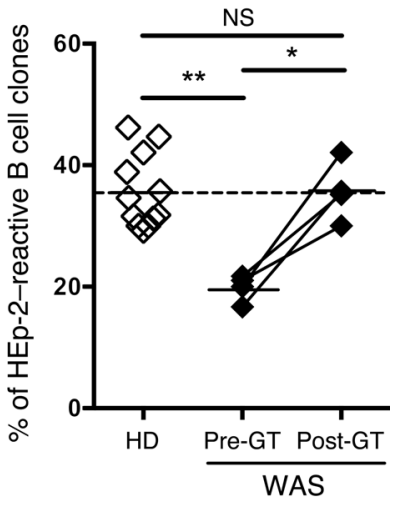

E

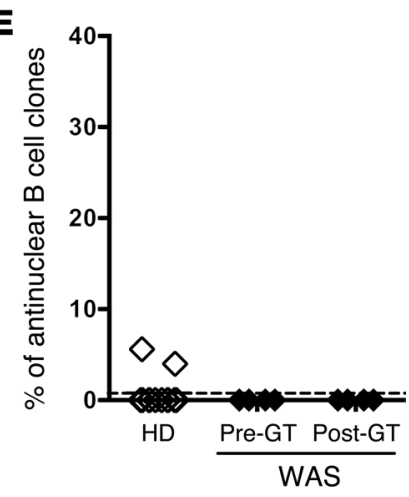

Figure 5. Central B cell tolerance is restored in WAS patients after GT treatment. (A and C) Recombinant antibodies in new emigrant/transitional B cells from 4 GT-treated WAS patients were tested by ELISA for reactivity against dsDNA, insulin, LPS (A), and HEp-2 lysate (C). Antibodies were considered polyreactive when they recognized all 3 antigens in $\mathbf{A}$. Dotted lines show ED38+ control, and horizontal lines define cutoff $\mathrm{OD}_{405}$ for positive reactivity. The frequencies of reactive and nonreactive clones are summarized in pie charts, with the total number of clones tested shown in the center. Frequencies of polyreactive (B), HEp-2-reactive (D), and antinuclear (E) new emigrant/transitional B cells in HDs, WAS patients, and WAS GT patients. Each symbol represents an individual, and horizontal bars display means. (B, D, and E) Differences between patients and HDs were analyzed for statistical significance using the Mann-Whitney test. Differences between samples before and after GT were analyzed using paired $t$ tests. ${ }^{*} P<0.05$ and ${ }^{* *} P<0.01$. 
A

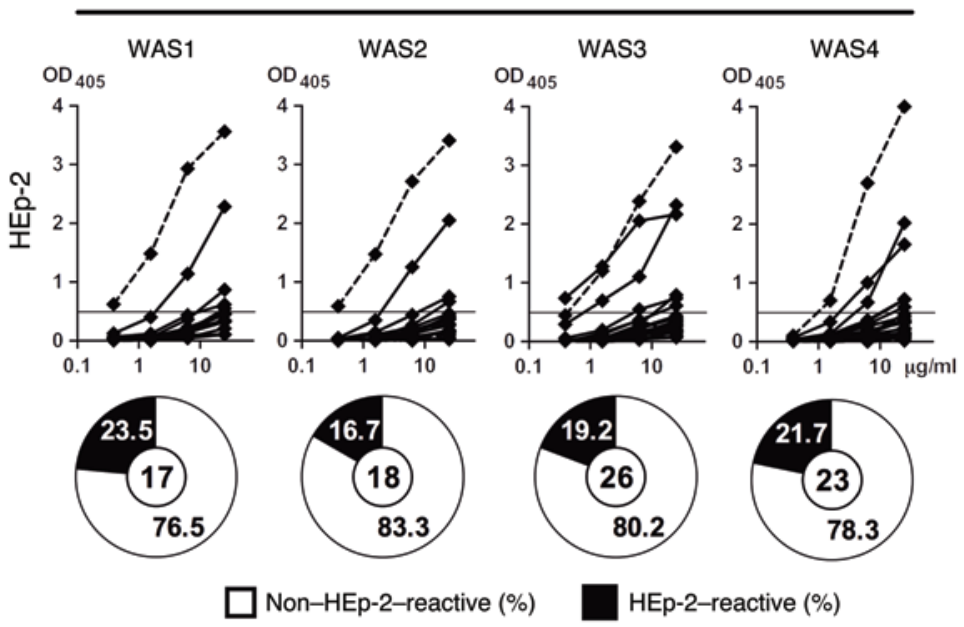

D
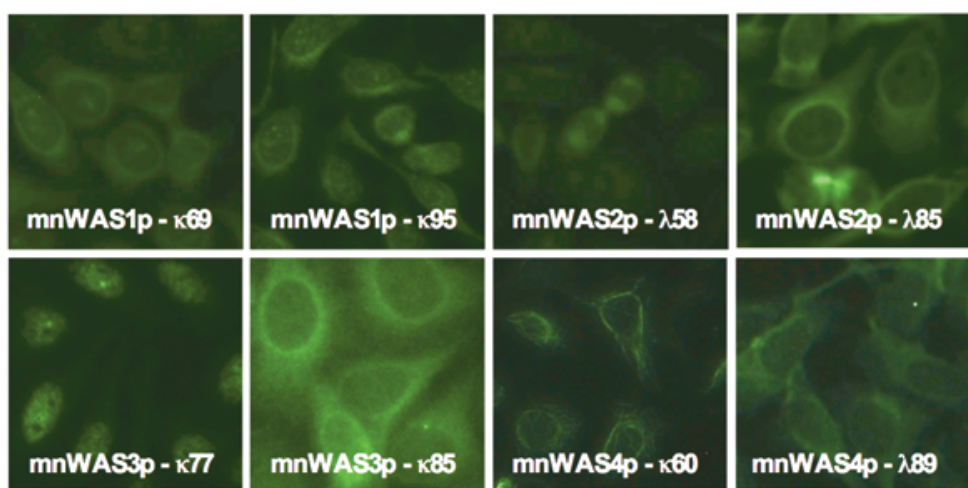

B
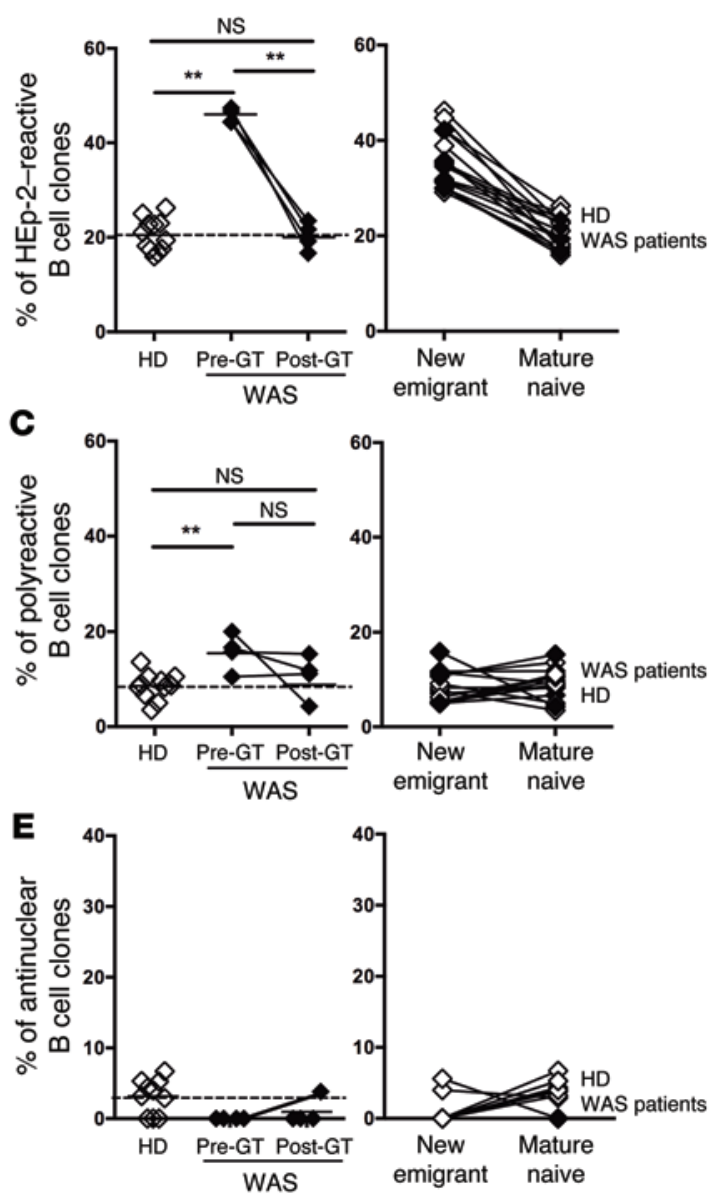

Figure 6. GT treatment restores peripheral B cell tolerance checkpoint in WAS patients. (A) Recombinant antibodies expressed by mature naive (CD19+ $\left.\mathrm{CD}^{-}{ }^{-} \mathrm{CD} 21^{+} \mathrm{IgM}{ }^{+} \mathrm{CD} 27^{-}\right)$B cells from 4 WAS GT-treated patients were tested by ELISA for reactivity against HEp-2 cell lysate. Dotted lines show ED38 ${ }^{+}$control. Horizontal lines show cutoff $\mathrm{OD}_{405}$ for positive reactivity. The frequencies of $\mathrm{HEp}$-2-reactive and non-HEp-2-reactive clones are summarized in the pie charts, with the number of antibodies tested shown in the center. The frequencies of HEp-2-reactive (B), polyreactive (C), and antinuclear (E) mature naive B cells in HDs and WAS patients before and after GT are represented (left panels). The evolution of the frequencies of HEp-2-reactive (B), polyreactive (C), and antinuclear (E) B cell clones between new emigrant and mature naive B cells in HDs (open diamonds) and post-GT WAS patients (filled diamonds) is shown in the right panels. Each symbol represents an individual, and horizontal bars display means. (D) Autoreactive antibodies expressed by mature naive $B$ cells in post-GT WAS patients mostly recognize cytoplasmic structures, besides mnWAS3p- $k 77$ with ANA reactivity. Original magnification, $\times 40$. (B, C, and E) Differences between patients and HDs were analyzed for statistical significance using the Mann-Whitney test. Differences between samples before and after GT were analyzed using paired $t$ tests. ${ }^{* *} P<0.01$.

CD3, CD28, and CD2 monoclonal antibodies of CFSE-labeled $\mathrm{CD} 4{ }^{+} \mathrm{CD} 25^{-}$Tresp cells from HDs or WAS patients. We found that Tregs from WAS patients had a significantly decreased ability to suppress Tresp cell proliferation compared with Tregs from HD controls, regardless of the origin of Tresp cells (Figure 4, C and D). In addition, Tresp cells from HDs and patients were similarly suppressed by Tregs from HDs, revealing that $\mathrm{T}$ cells from WAS patients are not refractory to suppression (Figure 4, C and D). Altogether, these results indicate that WASp mutation affects Treg phenotype and function.

Central B cell tolerance checkpoint is restored after HSC gene therapy in WAS patients. Lentiviral-mediated WAS gene transfer was recently shown to be a new therapy for WAS patients and restore lymphocyte development (30). To assess whether newly generated B cells are normally selected in the BM after gene therapy (GT), we analyzed the reactivity of antibodies expressed by new emigrant/transitional B cells isolated from the same 4 WAS patients described above 1-2 years after GT (Supplemental Table 1 and Supplemental Figure 1 for gating strategy) (30). All patients show a multilineage engraftment of transduced HSCs, with the WASp expression progressively increasing and persisting in the different hematopoietic cell lineages, likely reflecting a selective advantage in the periphery for WAS gene-corrected cells (31). Differences in IgH repertoire from pre-GT WASp-deficient new emigrant/transitional B cells were no longer significant after GT when compared with HDs, suggesting an improvement in B cell selection in the BM (Supplemental Figure 2). We found that new emigrant/transitional $\mathrm{B}$ cells isolated from patients after GT expressed a proportion of polyreactive antibodies that was now similar to that of HDs, suggesting that central B cell tolerance was better established after GT (Figure 5, A and B, and Supplemental Tables 10-13). 
A
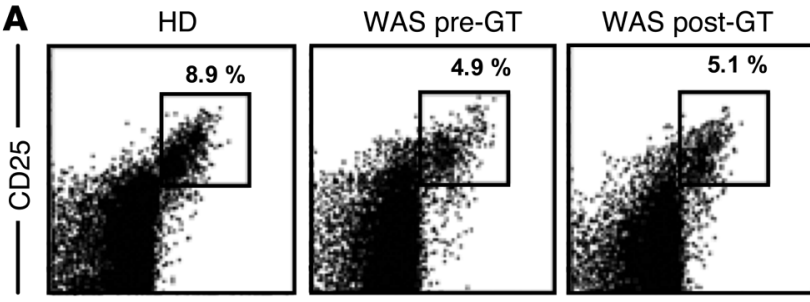

B

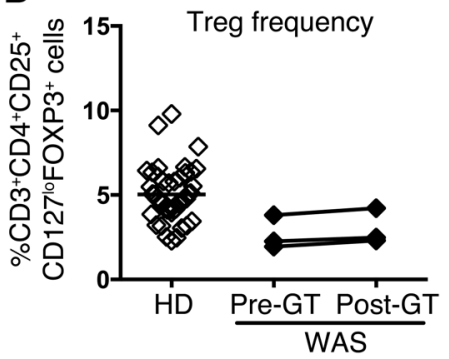

C
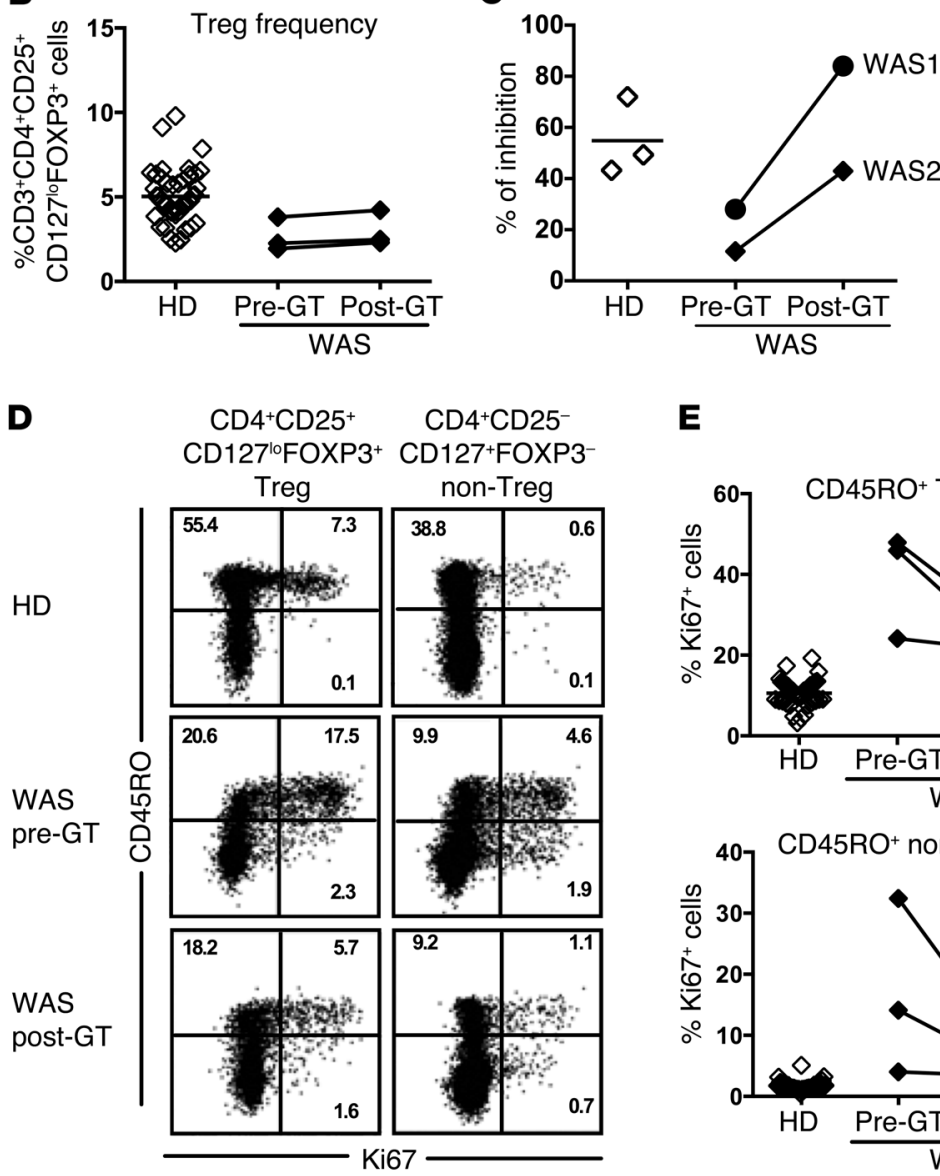

E
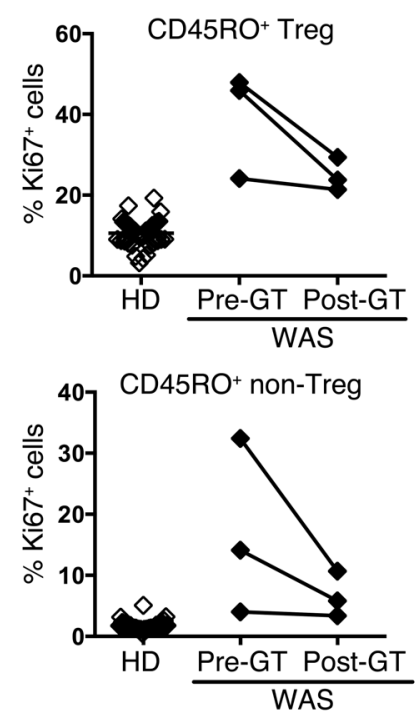

Figure 7. GT restores altered Treg function in WAS patients. (A) Representative flow cytometry dot plots showing the analysis of CD25 and FOXP3 expression when gating on $\mathrm{CD} 4^{+}$cells from a $\mathrm{HD}$ and a WAS patient before and after $\mathrm{GT}$. The frequency of $\mathrm{CD}^{+} \mathrm{CD} 4^{+} \mathrm{CD} 25^{+} \mathrm{C}-$ $\mathrm{D}^{2} 7^{\mathrm{I}} \mathrm{FOXP3} 3^{+}$Treg and their autologous suppressive activity in WAS patients before and after GT is shown in B and C, respectively. (D) Representative flow cytometry dot plots show the analysis of CD45RO and Ki67 in gated $\mathrm{CD} 4{ }^{+} \mathrm{CD} 25^{+} \mathrm{CD} 127^{\circ} \mathrm{FOXP3} 3^{+}$Treg (left panel) or CD4 ${ }^{+}$CD25-CD127+FOXP3- non-Treg (right panel) in a HD and a WAS patient before and after GT. (E) The evolution of $\mathrm{Ki}^{2} 7^{+}$cells among CD45RO+ Tregs or non-Tregs from 3 WAS patients before and after GT is compared with Ki67 expression in counterparts from $45 \mathrm{HD}$ controls.

Gene therapy corrects peripheral B cell-tolerance defects in WAS patients. To determine if GT could also restore the peripheral B cell tolerance checkpoint, we tested the reactivity of recombinant antibodies cloned from mature naive B cells of GT-treated WAS patients. In agreement with the normalization of $\mathrm{IgH}$ repertoire abnormalities in post-GT mature naive B cells, all treated patients displayed a significantly decreased frequency (16.7\%-23.5\%) of HEp-2-reactive mature naive B cells after GT compared with $42.1 \%-46.7 \%$ before GT (Figure 6, A and B, Supplemental Figure 2, and Supplemental Tables 14-17). These frequencies after GT display averages within the $16 \%-26.3 \%$ HD range, suggesting that the peripheral B cell selection step may be functional in the presence of lentiviral-encoded functional WASp (Figure 6, A and B). A tendency to the normalization of the peripheral $B$ cell tolerance checkpoint was further evidenced by the decreased frequency of polyreactive clones in the mature naive B cell compartments in 3 out of 4 patients after GT, reaching values comparable to those in HDs (Figure 6C and Supplemental Figure 7). Of note, ANAexpressing clones remained rare after GT (Figure 6, D and E), and the few cytoplasm-reactive clones

The proportion of polyreactive antibodies after GT was slightly increased compared with their B cell counterparts before GT (5\%-15.8\% in WAS patients after GT compared with $5 \%-11.5 \%$ in HDs), although differences did not reach statistical significance. Correction by GT of the enhanced removal of developing autoreactive $\mathrm{B}$ cells in the $\mathrm{BM}$ was further evidenced by the significant increase in the frequency (30\%-42.1\%) of HEp-2reactive new emigrant/transitional B cells in WAS patients after GT compared with $16.7 \%-21.7 \%$ in the patients before treatment (Figure 5, C and D). These proportions of HEp-2-reactive new emigrant/transitional B cells after GT were now similar to those (29.2\%-44.7\%) of HDs (Figure 5, C and D). No difference was observed in the frequency of $\mathrm{ANA}^{+} \mathrm{B}$ cell clones before and after GT, which remained virtually undetectable (Figure 5E). We conclude that the restoration of WASp expression in HSCs of WAS patients after GT leads to the normalization of the central B cell tolerance checkpoint. were weakly positive by immunofluorescence (Figure 6D). Interestingly, Treg function, which plays an important role in the regulation of this peripheral B cell tolerance checkpoint $(24,26)$, was found restored in 2 WAS patients after GT while Treg frequencies before and after GT appeared similar (Figure 7, A-C) (30). In agreement with this observation, we found a decreased Ki67 expression by Tregs and other T cells from WAS patients after GT, revealing a normalization of the homeostasis of these T cell compartments by the expression of functional WASp (Figure 7, D and E). Thus, GT restores the functionality of the peripheral B cell tolerance checkpoint in WAS patients, correlating with the correction of Treg suppression defects observed after GT treatment.

\section{Discussion}

We report here that WAS patients suffer from dysregulated central and peripheral B cell tolerance checkpoints, which are restored after lentiviral-mediated WAS gene transfer. Hence, 
WASp plays an important role in the regulation of these early developmental steps responsible for the selection of B cells and their antibody repertoire.

The regulation of central $\mathrm{B}$ cell tolerance appears to involve intrinsic B cell molecules involved in sensing binding to self-antigens and which include BCRs and potentially TLRs (25). Indeed, alterations in BCR signaling and/or TLR function in immunodeficient patients with mutations in genes encoding Bruton's tyrosine kinase, adenosine deaminase (ADA), IRAK4, MYD88, or TACI result in defective $\mathrm{B}$ cell responses to these receptors and correlate with the impaired removal of developing autoreactive clones that escape central B cell tolerance $(22-24,36)$. In contrast, all WAS patients before HSC-GT displayed a more stringent central B cell tolerance checkpoint, as evidenced by the enhanced removal of developing autoreactive clones that expressed either polyreactive or HEp-2-reactive antibodies. The first identification in humans, to our knowledge, of a hyperactive counterselection step for autoreactive clones in the $\mathrm{BM}$ of WAS patients correlates with their enhanced BCR function. These findings further support the model in which BCR binding to self-antigens plays a key role in the induction of tolerance mechanisms, such as receptor editing or deletion, leading to the silencing of autoreactive B cells. The modest increase in TLR7 and TLR9 responses in human WASp-deficient $\mathrm{B}$ cells is a feature that has been previously reported in murine $\mathrm{B}$ cells, as well as plasmacytoid DCs $(9,37)$, and that may also contribute to the increased removal of autoreactive clones at the central B cell tolerance checkpoint. In conclusion, WASp expression in developing B cells is important to establish proper thresholds for autoreactive B cell silencing in the BM.

WASp is a regulator of actin dynamics and may therefore affect the signaling and trafficking of BCRs and TLRs $(38,39)$. Actin remodeling is associated with BCR signaling and requires Vav, PLC $\gamma 2$, and Btk, which activate the Rho family GTPases Rac and Cdc42 that bind WASp $(38,39)$. The absence of functional WASp may therefore interfere with actin remodeling and result in increased BCR function. In line with this hypothesis is the decreased BCR internalization that correlated with increased calcium mobilization in mouse $\mathrm{B}$ cells harboring a specific deletion of WASp (9). Interestingly, we found increased BCR expression on mature naive B cells from WAS patients. Thus, the absence of functional WASp results in increased BCR signaling, which likely affects the removal of developing autoreactive $B$ cells and $B$ cell activation at later stages of $\mathrm{B}$ cell development.

The more stringent central B cell tolerance checkpoint and the dearth of autoreactive immature B cells exiting the BM of WAS patients appeared paradoxical because these patients are characterized by a break in B cell tolerance and the production of autoreactive antibodies (4). However, we found that WAS patients also suffer from an impaired peripheral B cell tolerance checkpoint, resulting in an increase in autoreactive clones in their mature naive B cell compartment. This emergence of polyreactive and HEp-2-reactive B cells between the new emigrant/transitional and mature naive $B$ cell stages reveals that these self-reactive clones are positively selected in the absence of functional WASp. A similar faulty selection of mature naive B cells was observed in CD4OL-, FOXP3-, and DOCK8-deficient patients, as well as in patients with common-variable immunodeficiency who displayed decreased frequencies of Tregs, nonfunctional Tregs, or both $(24,26,27,29)$. In agreement with these data, the defective peripheral B cell tolerance checkpoint in WAS patients was associated with Tregs displaying an abnormal phenotype and showing defect in homeostasis regulation and suppressive capacities. WAS patients' Tregs exhibited an activated phenotype illustrated by increased CTLA4 expression and contained an increased proportion of $\mathrm{Ki}^{+} 7^{+}$proliferating clones in the patients' $\mathrm{CD}_{45 \mathrm{RO}^{+}}$Tregs, a feature associated with proinflammatory cytokine production combined with reduced suppressive capabilities (32-35). Indeed, $\mathrm{CD} 4{ }^{+} \mathrm{CD} 25^{\mathrm{hi}} \mathrm{CD} 127^{\text {lo }}$ Tregs from WAS patients showed impaired suppressive activity, further supporting previous observations obtained with $\mathrm{CD} 44^{+} \mathrm{CD} 25^{\text {hi }} \mathrm{T}$ cells (5-8). In particular, it has been demonstrated that Tregs lacking WASp showed a reduced ability to suppress B cell activation and proliferation (40), thus suggesting that Treg failure could contribute to the altered B cell tolerance observed in WAS patients and mouse counterparts. While WAS mutations enhance BCR/ TLR functions, many reports demonstrated decreased $\mathrm{T}$ cell receptor responses (TCR responses), including diminished IL-2 production in WASp-deficient T cells (41-43). Hence, decreased TCR responsiveness and IL-2 production in WAS patients may also be responsible for their abnormal Treg function. We conclude that the defective peripheral B cell tolerance checkpoint in WAS patients is likely explained by qualitative defects in Tregs in the absence of functional WASp.

HSC-GT using lentiviruses has recently been reported to improve WAS patients' clinical condition and results in robust and stable multilineage engraftment of transduced cells (30). In addition to this quantitative reconstitution of hematopoietic lineages including B cells, we found that HSC-GT restores both central and peripheral B cell tolerance checkpoints. HSC-GT also corrected the abnormal central and peripheral $\mathrm{B}$ cell tolerance in ADA-SCID patients, further supporting the qualitative efficacy of this treatment $(22-24,36)$. Since central B cell tolerance requires proper $\mathrm{BCR}$ and TLR function, our data suggest that gene correction of WASp-deficient B cells by lentiviral HSC-GT may lead to the normalization of BCRs, thereby reestablishing proper thresholds for the removal of developing autoreactive $\mathrm{B}$ cells. As a consequence, HSC-GT results in a decreased proportion of new emigrant/transitional B cells exiting the BM that was reported to be increased in WAS patients (31). HSC-GT also corrected the second $\mathrm{B}$ cell selection step that occurs between new emigrant/transitional and mature naive B cell stages. The restoration of Treg function in WAS patients after GT correlates with proper peripheral B cell selection and prevents the accumulation of autoreactive clones in their blood, further revealing that Tregs are responsible for the regulation of this peripheral checkpoint $(24,26,29)$. As part of tolerance restoration, the global homeostasis of T cell compartments, including Tregs, was improved in WAS patients after GT, as illustrated by the decreased expression of Ki67 proliferation marker by their T cells, likely resulting from the presence of functional Tregs.

In summary, we demonstrated that WASp plays an essential role in the establishment of early B cell tolerance in humans and that lentiviral-mediated gene correction of WASp restores both central and peripheral B cell tolerance checkpoints in WAS patients. 


\section{Methods}

Patients. Characteristics of WAS patients treated by GT are described in Supplemental Table 1. GT for WAS was performed as previously described (30). The 4 WAS patients treated by GT, described in this study, are reported in the same order in Aiuti et al. (WAS1-3; ref. 30) and in Castiello et al. (WAS1-4; ref. 31). Additional WAS patients were enrolled to analyze B and T cell responses in vitro and included WAS6 (31 years old) and WAS 51 (10 years old) with c.256C >T (p.Cys256Thr) WAS mutation and Zhu scores of 5A and 2, respectively; WAS52 (12 years old) with c.820-835dup16 WAS mutation and a Zhu score of 2; WAS58 (3 years old) with c.778-6G>A WAS mutation and a Zhu score of 2; and WAS patients Y2 (2 years old), Y6 (9 years old), and Y7 (76 years old) with pHis30del WAS mutation and Zhu scores of 2, 2, and 4, respectively. HDs were previously reported, except HD30, who is a 47-year-old female of mixed European descent (Supplemental Tables 18 and 19).

Cell staining and sorting. Peripheral B cells were purified from the blood of patients and HDs by positive selection using CD20-magnetic beads (Miltenyi Biotec). Enriched B cells were stained with the following antibodies: anti-CD19-Pacific Blue (clone HIB19), anti-CD27-PercP-Cy5.5 (clone O323), anti-CD10-PE-Cy7 (clone HI10a) (all from BioLegend), anti-CD21-APC (clone B-ly4), and anti-IgM-FITC (clone G20-127) (from BD Biosciences). Single CD19 ${ }^{+} \mathrm{CD} 10^{+} \operatorname{IgM}^{\mathrm{hi}} \mathrm{CD} 21^{\mathrm{lo}} \mathrm{CD} 27^{-}$ new emigrant/transitional and $\mathrm{CD} 19^{+} \mathrm{CD} 10^{-} \mathrm{CD} 21^{+} \mathrm{IgM}^{+} \mathrm{CD} 21^{+} \mathrm{CD} 27$ peripheral mature naive $\mathrm{B}$ cells from patients and HDs were sorted on a FACSAria flow cytometer (BD Biosciences) into 96-well PCR plates.

cDNA, RT-PCR, antibody production, ELISAs, and indirect fluorescence assays. RNA from single cells was reverse-transcribed in the original 96-well plate in $12.5 \mu \mathrm{l}$ reactions containing $100 \mathrm{U}$ Superscript II RT (Invitrogen) for 45 minutes at $42^{\circ} \mathrm{C}$. Reverse transcription PCR (RT-PCR) reactions, primer sequences, cloning strategy, expression vectors, antibody expression, and purification were performed as previously described (21, 44). Antibody reactivity was tested by ELISA as previously described (21, 44). Highly reactive ED38 was used as positive control in HEp-2 reactivity and polyreactivity ELISA $(21,44)$. Antibodies were considered polyreactive when they recognized all 3 analyzed antigens: dsDNA, insulin, and LPS. For indirect immunofluorescence assays, HEp-2 cell-coated slides (BION Enterprises Ltd.) were incubated in a moist chamber at room temperature with purified antibodies at $50-100 \mu \mathrm{g} / \mathrm{ml}$ and detected using FITC-conjugated goat anti-human IgG.

$B$ cell activation assay. Naive B cells were seeded in 384-well flat-bottom plates at a concentration of 50,000 cells/well in RPMI 10\% FBS and $2 \mu \mathrm{g} / \mathrm{ml}$ or $0.7 \mu \mathrm{g} / \mathrm{ml} \mathrm{F}\left(\mathrm{ab}^{\prime}\right)$, rabbit anti-human IgM (Jackson ImmunoResearch Laboratories Inc.), $2 \mu \mathrm{g} / \mathrm{ml}$ or $0.75 \mu \mathrm{g} / \mathrm{ml}$ gardiquimod (InvivoGen), or $0.5 \mu \mathrm{g} / \mathrm{ml}$ or $0.3 \mu \mathrm{g} / \mathrm{ml} \mathrm{CpG} \mathrm{ODN2006}$ (Invitrogen) for 2 days. Flow cytometry analysis was performed using anti-CD25-FITC (clone BC96), anti-CD86-APC (clone IT2.2), anti-TACI-PE (clone 1A1), anti-CD69-PE-Cy7 (clone FN50), anti-CD27-PerCP-Cy5.5 (clone O323), anti-CD19 APC-Cy7 (clone HIB19) (all BioLegend), and antiCD21-Pacific Blue (clone B-ly4, BD Biosciences).

In vitro Treg suppression assay. $\mathrm{CD}^{+} \mathrm{T}$ cells were enriched using the EasySep Human $\mathrm{CD}^{+} \mathrm{T}$ cell enrichment kit (StemCell Technologies Inc.). Only in the case of pre- and post-GT samples of patient WAS2, the
$\mathrm{CD}^{+}{ }^{+} \mathrm{CD} 25^{+}$Regulatory T Cell Isolation Kit (Miltenyi Biotec) was used to isolate Tregs. In all other patients' samples, $\mathrm{CD} 4^{+} \mathrm{CD} 25^{\mathrm{hi}} \mathrm{CD} 127^{\mathrm{lo} /-}$ Tregs were sorted by flow cytometry, whereas $\mathrm{CD} 3^{+} \mathrm{CD} 4^{+} \mathrm{CD} 25^{-}$Tresp cells were obtained after the depletion of $\mathrm{CD} 25^{+}$cells with anti-human CD25 microbeads (Miltenyi Biotec) and then labeled with CellTrace CFSE (InvivoGen) at $5 \mu \mathrm{M}$. Treg and Tresp cells were cocultured at a 1:1 ratio in the presence of beads loaded with anti-CD2, anti-CD3, and anti-CD28 (Treg Suppression Inspector, Human; Miltenyi Biotec). At 3.5-4.5 days, cocultures were stained for viability with the LIVE/DEAD kit (Invitrogen), and proliferation of the viable Tresp was analyzed by CFSE dilution. The following antibodies were used for flow cytometric stainings on T cells: anti-CD4-APC-Cy7 (clone OKT4), anti-CD25 PE and PE-Cy7 (clone BC96), anti-CD127 PerCP-Cy5.5 (clone AO19D5), anti-CD45RO Pacific Blue (clone UCHL1) (all from BioLegend), anti-CTLA4/CD152PE (clone UC10-4F10-11, BD Biosciences), and anti-CD3 eFluor 605NC (OKT3, eBioscience). Intracellular staining with anti-FOXP3 Alexa Fluor 488 was performed using the Foxp3/Transcription Factor Staining Buffer Set (eBioscience), in accordance with the manufacturer's instructions.

Statistics. Differences between patients and HDs were analyzed for statistical significance using the Mann-Whitney test. Differences between samples before and after GT were analyzed using paired $t$ tests. A $P$ value less than 0.05 was considered significant.

Study approval. All samples were collected in accordance with the Code of Ethics of the World Medical Association (Declaration of Helsinki) and institutional review board-reviewed protocols. GT studies refer to the clinical protocol (ClinicalTrials.gov, NCT01515462) whose criteria of eligibility have been previously described (30). All legal representatives gave written informed consent.

\section{Acknowledgments}

We thank L. Devine and C. Wang for cell sorting, and R. Sokolic and E. Garabedian for help enrolling patients. This work was supported by Italian Telethon Foundation (TIGET Core grant A2) (to A. Villa), Ministero della Salute (GR-2009-1579814) (to M. Bosticardo), EU project CELL PID (FP7 project 261387) (to A. Aiuti and A. Villa), and grants AI061093, AI071087, AI082713, and AI095848 from NIH-NIAID (to E. Meffre). H. Morbach received support from the German Research Foundation (DFG, MO 2160/2-1). N. Romberg received support from the NIH-NIAID (AI115001-01). Since January 2014, GlaxoSmithKline has in-licensed the WAS gene therapy program and has become the financial sponsor of the clinical trial conducted at TIGET. We thank all the medical staff of the HSR-TIGET Pediatric Clinical Research Unit, Pediatric Immunohematology, and BM Transplant Unit. We are indebted to the patients and their families for their commitment and cooperation.

Address correspondence to: Anna Villa, San Raffaele TIGET, IRCCS San Raffaele Scientific Institute, via Olgettina 58, 20132, Milan, Italy. Phone: 39.02.26435273; E-mail: villa.anna@hsr.it. Or to: Eric Meffre, Yale University School of Medicine, 300 George Street, New Haven, Connecticut 06511, USA. Phone: 203.737.4535; E-mail: eric.meffre@yale.edu.
1. Bosticardo M, Marangoni F, Aiuti A, Villa A, Grazia Roncarolo M. Recent advances in understanding the pathophysiology of Wiskott-Aldrich syndrome. Blood. 2009;113(25):6288-6295.
2. Thrasher AJ, Burns SO. WASP: a key immunological multitasker. Nat Rev Immunol. 2010;10(3):182-192.

3. Imai K, et al. Clinical course of patients with WASP gene mutations. Blood. 2004;103(2):456-464.

4. Catucci M, Castiello MC, Pala F, Bosticardo M, Villa A. Autoimmunity in Wiskott-Aldrich syndrome: an unsolved enigma. Front Immunol. 
2012;3:209.

5. Marangoni F, et al. WASP regulates suppressor activity of human and murine CD4(+)CD25(+) FOXP3(+) natural regulatory T cells. J Exp Med. 2007;204(2):369-380

6. Maillard MH, et al. The Wiskott-Aldrich syndrome protein is required for the function of CD4(+)CD25(+)Foxp3(+) regulatory T cells. J Exp Med. 2007;204(2):381-391.

7. Adriani $M$, et al. Impaired in vitro regulatory $T$ cell function associated with Wiskott-Aldrich syndrome. Clin Immunol. 2007;124(1):41-48.

8. Humblet-Baron S, et al. Wiskott-Aldrich syndrome protein is required for regulatory $\mathrm{T}$ cell homeostasis. JClin Invest. 2007;117(2):407-418.

9. Becker-Herman S, et al. WASp-deficient B cells play a critical, cell-intrinsic role in triggering autoimmunity. J Exp Med. 2011;208(10):2033-2042.

10. Recher M, et al. B cell-intrinsic deficiency of the Wiskott-Aldrich syndrome protein causes severe abnormalities of the peripheral B cell compartment in mice. Blood. 2012;119(12):2819-2828.

11. Bosticardo $\mathrm{M}$, et al. Lentiviral-mediated gene therapy leads to improvement of $\mathrm{B}$ cell functionality in a murine model of Wiskott-Aldrich syndrome. JAllergy Clin Immunol. 2011;127(6):1376-1384 .

12. Facchetti F, et al. Defective actin polymerization in EBV-transformed B cell lines from patients with the Wiskott-Aldrich syndrome. J Pathol. 1998;185(1):99-107.

13. Sic $\mathrm{H}$, et al. Sphingosine-1-phosphate receptors control B cell migration through signaling components associated with primary immunodeficiencies, chronic lymphocytic leukemia, and multiple sclerosis. JAllergy Clin Immunol. 2014;134(2):420-428.

14. Castiello MC, et al. Wiskott-Aldrich Syndrome protein deficiency perturbs the homeostasis of B cell compartment in humans. JAutoimmun. 2014;50:42-50.

15. Sullivan KE, Mullen CA, Blaese RM, Winkelstein JA. A multiinstitutional survey of the Wiskott-Aldrich syndrome. JPediatr. 1994;125(6 pt 1):876-885.

16. Buchbinder D, Nugent DJ, Fillipovich AH. Wiskott-Aldrich syndrome: diagnosis, current management, and emerging treatments. Appl Clin Genet. 2014;7:55-66.

17. Simon KL, Anderson SM, Garabedian EK, Moratto D, Sokolic RA, Candotti F. Molecular and phenotypic abnormalities of $B$ lymphocytes in patients with Wiskott-Aldrich syndrome. J Allergy Clin Immunol. 2013;133(3):896-899.

18. Isnardi I, et al. Complement receptor $2 /$
CD21- human naive B cells contain mostly autoreactive unresponsive clones. Blood. 2010;115(24):5026-5036.

19. Silberstein LE, et al. Variable region gene analysis of pathologic human autoantibodies to the related $\mathrm{i}$ and I red blood cell antigens. Blood. 1991;78(9):2372-2386.

20. Pascual V, et al. Nucleotide sequence analysis of the $\mathrm{V}$ regions of two IgM cold agglutinins. Evidence that the VH4-21 gene segment is responsible for the major cross-reactive idiotype. J Immunol. 1991;146(12):4385-4391.

21. Wardemann H, Yurasov S, Schaefer A, Young JW, Meffre E, Nussenzweig MC. Predominant autoantibody production by early human B cell precursors. Science. 2003;301(5638):1374-1377.

22. Ng YS, Wardemann H, Chelnis J, Cunningham-Rundles C, Meffre E. Bruton's tyrosine kinase is essential for human B cell tolerance. $J$ Exp Med.2004;200(7):927-934.

23. Isnardi I, et al. IRAK-4- and MyD88-dependent pathways are essential for the removal of developing autoreactive B cells in humans. Immunity. 2008;29(5):746-757.

24. Romberg N, et al. CVID-associated TACI mutations affect autoreactive $\mathrm{B}$ cell selection and activation. J Clin Invest. 2013;123(10):4283-4293.

25. Meffre $\mathrm{E}$. The establishment of early B cell tolerance in humans: lessons from primary immunodeficiency diseases. Ann N Y Acad Sci. 2011;1246:1-10.

26. Kinnunen T, et al. Accumulation of peripheral autoreactive $\mathrm{B}$ cells in the absence of functional human regulatory T cells. Blood. 2013;121(9):1595-1603.

27. Herve M, et al. CD4O ligand and MHC class II expression are essential for human peripheral B cell tolerance. JExp Med. 2007;204(7):1583-1593.

28. Menard L, et al. Signaling lymphocytic activation molecule (SLAM)/SLAM-associated protein pathway regulates human $B$ cell tolerance. J Allergy Clin Immunol. 2014;133(4):1149-1161.

29. Janssen E, et al. Dedicator of cytokinesis 8-deficient patients have a breakdown in peripheral B cell tolerance and defective regulatory $\mathrm{T}$ cells. JAllergy Clin Immunol. 2014;134(6):1365-1374.

30. Aiuti A, et al. Lentiviral hematopoietic stem cell gene therapy in patients with Wiskott-Aldrich syndrome. Science. 2013;341(6148):1233151.

31. Castiello MC, et al. B cell reconstitution after lentiviral vector-mediated gene therapy in patients with Wiskott-Aldrich syndrome. J Allergy Clin Immunol. 2015;S0091-6749(3)(15)00179-7.

32. Jabara $\mathrm{HH}$, et al. DOCK8 functions as an adaptor that links TLR-MyD88 signaling to B cell activation. Nat Immunol. 2012;13(6):612-620.

33. Saadoun D, et al. Expansion of autoreactive unresponsive CD21-/low B cells in Sjogren's syndrome-associated lymphoproliferation. Arthritis Rheum. 2013;65(4):1085-1096.

34. Terrier B, et al. Expansion of functionally anergic CD21-/low marginal zone-like $\mathrm{B}$ cell clones in hepatitis $C$ virus infection-related autoimmunity. J Immunol. 2011;187(12):6550-6563.

35. Meyers G, et al. Activation-induced cytidine deaminase (AID) is required for $\mathrm{B}$ cell tolerance in humans. Proc Natl Acad Sci US A. 2011;108(28):11554-11559.

36. Sauer AV, et al. Alterations in the adenosine metabolism and CD39/CD73 adenosinergic machinery cause loss of Treg cell function and autoimmunity in ADA-deficient SCID. Blood. 2012;119(6):1428-1439.

37. Prete F, et al. Wiskott-Aldrich syndrome proteinmediated actin dynamics control type-I interferon production in plasmacytoid dendritic cells. JExp Med. 2013;210(2):355-374.

38. Batista FD, Treanor B, Harwood NE. Visualizing a role for the actin cytoskeleton in the regulation of B cell activation. Immunol Rev. 2010;237(1):191-204.

39. Song W, Liu C, Upadhyaya A. The pivotal position of the actin cytoskeleton in the initiation and regulation of $\mathrm{B}$ cell receptor activation. Biochim Biophys Acta. 2014;1838(2):569-578.

40. Adriani M, et al. Defective inhibition of B cell proliferation by Wiskott-Aldrich syndrome protein-deficient regulatory T cells. Blood. 2011;117(24):6608-6611.

41. Cannon JL, Burkhardt JK. Differential roles for Wiskott-Aldrich syndrome protein in immune synapse formation and IL-2 production. J Immunol. 2004;173(3):1658-1662.

42. Cianferoni A, et al. Defective nuclear translocation of nuclear factor of activated T cells and extracellular signal-regulated kinase underlies deficient IL-2 gene expression in Wiskott-Aldrich syndrome. J Allergy Clin Immunol. 2005;116(6):1364-1371.

43. Trifari S, et al. Defective Th1 cytokine gene transcription in $\mathrm{CD} 4^{+}$and $\mathrm{CD} 8^{+} \mathrm{T}$ cells from Wiskott-Aldrich syndrome patients. JImmunol. 2006;177(10):7451-7461.

44. Meffre E, Schaefer A, Wardemann H, Wilson P, Davis E, Nussenzweig MC. Surrogate light chain expressing human peripheral B cells produce self-reactive antibodies. J Exp Med. 2004;199(1):145-150. 